\title{
ALFABETIZAÇÃO NO ı CICLO DO ENSINO FUNDAMENTAL
}

\author{
Cleidiane Gonçalves da Silva ${ }^{1}$ \\ Cristiane Moraes Pimentel ${ }^{2}$ \\ Eliane Maria de Lima Paixão ${ }^{3}$ \\ Jucilene Pinto de Campos ${ }^{4}$ \\ Sandra Aparecida Nogueira ${ }^{5}$
}

RESUMO: Este artigo teve como objetivo identificar conceitos e práticas de letramento, analisando seus efeitos na apropriação da linguagem escrita por crianças alfabetizadas. Verificamos que o trabalho pedagógico do alfabetizador favorece a apropriação do sistema de escrita de seus alunos, porém, enfatiza a necessidade de uma prática pedagógica que conceba a alfabetização como um processo construtivo, que permite às crianças conviver com a prática da leitura social e escrita.

Palavras-Chave: Concepções. Práticas. Alfabetização. Escrita.

ABSTRACT: This article aimed to identify literacy concepts and practices, analyzing their effects on the appropriation of written language by literate children. We found that the literacy teacher's pedagogical work favors the appropriation of the writing system of their students, however, it emphasizes the need for a pedagogical practice that sees literacy as a constructive process, which allows children to live with the practice of social reading and writing.

Keywords: Conceptions. Practices. Literacy. Writing.

\footnotetext{
I Graduada em Pedagogia pela Universidade Norte do Paraná - UNOPAR, Especialista em Educação Infantil com Ênfase nos Anos Iniciais pela Faculdade FAIPE

${ }^{2}$ Graduada em Pedagogia pela Universidade Federal de Mato Grosso - UFMT, Especialista em Educação Especial e Inclusão pelas Faculdades Integradas de Várzea Grande - FIAVEC.

${ }^{3}$ Graduada em Pedagogia pelas Faculdades Mato-grossenses de Ciências Sociais e Humanas, Especialista em Educação Infantil e Alfabetização pelo Instituto Cuiabano de Educação - ICE.

${ }^{4}$ Graduação em Pedagogia pela Faculdade Afirmativo.

${ }^{5}$ Graduada em Pedagogia pela Universidade Luterana do Brasil - ULBRA, Especialista em Educação Infantil pela Faculdade das Águas Emendadas - FAE.
} 


\section{INTRODUÇÃO}

No cenário da educação atual, as discussões sobre o processo de alfabetização tem ocupado papel central, dado a sua importância para a escolarização das crianças. Essas reflexões, até recentemente, se concentravam em torno de metodologias para o ensino da leitura e escrita. Sob esta ótica,o sucesso nas aprendizagens de ler e escrever dependia, primordialmente, do emprego de métodos de ensino. No entanto, as contribuições decorridas de diferentes áreas científicas permitiram redirecionar o olhar para o processo de aprendizagem, e, isso possibilitou o conhecimento do modo pelo qual a criança aprende a utilizar e interpretar a língua escrita, colocando a apropriação desse conhecimento sob um ponto de vista completo.

Neste artigo, analisa-se o processo de alfabetização traçando discussões sobre as práticas de ensino e aprendizagem presentes no cotidiano alfabetizador, discutindo os diferentes métodos utilizados para alfabetizar, bem como a que concepções estão fundamentados, apoiando essas reflexões em Barbosa (1994); Frade, (2007); e Morais

(2006), Ferreiro e Teberosky (1985); e Azenha (2006) destacando as contribuições acerca da psicogênese da escrita infantil e suas implicações para os processos de apropriação da língua.

Entende-se a importância que a aquisição do sistema alfabético de escrita representa para as crianças e é inegável a sua relevância e suas implicações para a escolarização destas. Portanto, realizar uma análise acerca dos processos e elementos que direcionam a prática docente alfabetizadora se torna fundamental por permitir a compreensão sobre como está ocorrendo esse processo sob um ponto de vista concreto, isto é, a partir do cotidiano alfabetizador.

\section{DESENVOLVIMENTO}

\section{I Métodos de Alfabetização}

Toda prática pedagógica traz consigo concepções que delimitam e conduzem os processos de ensino, aprendizagem e todo o trabalho didático realizado em sala de aula.A cada contribuição teórica, novas concepções ganham espaço no cenário escolar, 
trazendometodologias distintas para os processosde ensino e aprendizagem. No campo da alfabetização é visível a configura de diversas concepções, principalmente as tradicionais, que se apresentaram de maneira marcante no decorrer da história e, até os dias atuais, é possível perceber sua presença no ambiente alfabetizador.

O processo de ensino, nessa perspectiva, se dá por meio de métodos que são executados a partir de sequências rígidas para a aprendizagem. E por esse motivo, receberam inúmeras críticas. Todavia, sem orientações metodológicas para alfabetizar pode-se estar contribuindo para a ampliação do fracasso escolar e para o insucesso das crianças no acesso a cultura escrita. Desta forma, as metodologias devem compreender o ensino do sistema escritae contemplar as práticas sociais de leitura e escrita (SOARES, 2004).

Nas metodologias tradicionais para alfabetizar, podemos destacar as abordagens analítica e sintética. Os métodos sintéticos privilegiam a síntese como unidade principal para o ensino da língua escrita. Nele, o ensino parte de unidades menores à unidades maiores, compreendendo a aprendizagem da escrita como um processo cumulativo em que, sequencialmente, as crianças aprendem as letras, as sílabas, e assim, em direçãoao domínio do texto.Seguindo este princípio, podem ser destacadas três abordagens de ensino: o método de soletração ou alfabético; método fônico;e o método silábico.

O método alfabético ou de soletração elege como elemento de ensino a letra, e consiste na memorização do alfabeto. Seu ensino constitui-se pelo reconhecimento das letras de modo sequenciado, seguido da decoração das diversas combinações silábicas. Nesse processo de ensino, em que é privilegiada a memorização, a relação entre a fala (grafema) e a escrita (fonema) é negligenciado (FRADE, 2007). Em contrapartida, o método fônico traz como princípio base o ensino a partir dos sons letras. Nele, "cada letra é aprendida como um fonema (som) que junto a outro fonema, pode formar sílabas e palavras"(FRADE, 2007, p. 03). Nesse contexto, o ensino e a aprendizagem estãobaseados na relação som/letra e na decifração do textopara asua compreensão. Já nos métodos silábicos, o processo de ensino está centradona sílaba. Para isso, apresentam-se a forma e o nome das vogais, seguido dascombinações vocálicas e da combinação entre vogais e consoante, posteriormente, utilizadas para a formação de palavras (CORREAA, 2003, p. 3I). 
A valorização nessa metodologia desconsidera a importância do significado do texto para a aprendizagem.

Diante disso, Morais (2006) ressalta que os métodos sintéticos têm seu principio pautado na concepção empirista, isto é, a aprendizagem da língua escrita é entendida como um processo cumulativo, centrando-se nos aspectos da percepção e da memória. Pela sua ênfase nas discriminações auditivas e visuais e nos aspectos fonema-grafema, "o processo de aprendizagem de leitura é visto, simplesmente como uma associação entre respostas sonoras a estímulos gráficos" (FERREIRO; TABEROSKY, 1985, p. 20). Na busca por romper com o princípio empirista, a metodologia analítica traz como eixo norteador de ensino o reconhecimento global do texto/palavra para posterior decomposição de suas unidades. Nessa abordagem, o ensino se desenvolve através dos métodos de palavração, sentenciação e do global de contos ou historietas. No método de palavração o ensino é baseado no reconhecimento da palavra. Nessa orientação metodológica, as palavras são dispostas em categorias, de modo que o educando possareconhecê-las a partir de suas configurações gráficas, e "em suas aplicações, as figuras podem acompanhar as palavras, no início do processo, e sua repetição garante a memorização. Ao mesmo tempo em que são incentivadas estratégias de leitura" (FRADE, 2007, p.5).

No método de sentenciação a unidade de análise é a sentença. Em seu ensino, após o reconhecimento e compreensão, a sentença é decomposta em palavras que, por sua vez, é decomposta em sílabas. Já, o método global de contos ou historieta, elege como unidade básica para a aprendizagem o texto. Seu processo de ensino é realizado através do reconhecimento textual, para posterior decomposição emsegmentos menores. Sendo, seus principais exercícios voltados para a identificação de palavras. A perspectiva privilegiada nesses métodos é a percepção visual. É valorizada a leitura silenciosa e a cópia, e apesar da realização de leitura oral, o maior tempo é destinado as cópias (FRADE, 2007).

Esta valorização está respaldada na concepção associacionista, que segundo Barbosa (1994, p.70) entende a leitura e a escrita como"um comportamento complexo, que pode ser subdividido em uma cadeia de comportamentos simples; através do controle de respostas obtidas a partir dos estímulos apresentados, progressivamente, a criança aprende a ler e escrever”. Dessa maneira, tanto as metodologias empiristas quanto as associacionistas 
tiveram ampla repercussão nas discussões do campo educacional e no ambiente alfabetizador. À medida que eram postas novas questões e exigências sociais no contexto educacional, as discussões em torno da prática alfabetizadora foram gradativamente ampliadas, emergindo investigações que buscaram a compreensão do processo de aprendizagem da criança, deslocando a centralidade dos métodos de ensinoe trazendo contribuições significativas para o desenvolvimento de novas concepções e práticas de alfabetização.

\subsection{O ensino da língua escrita}

A partir da década de 1980 , as discussões acerca do processo de alfabetização foram ampliadas. Até esse período acreditava-se que a eficácia dessa aprendizagem, dependia, exclusivamente, do emprego de métodos. Isto significa, conforme Ferreiro (2001), que a apropriação da leitura e escrita decorria de fatores externos diante de um sujeito passivo. Como consequência, a língua escrita é apresentada "como um objeto imutável (não como o produto de uma prática histórica) e como um objeto 'em si' (não como um poderoso instrumento nas ações sociais)" (p. 22-23).Entretanto, as contribuições vindas de diversas áreas científicas (Psicologia, Psicolinguística, Linguística, Pedagogia), evidenciaram elementos importantes do processo alfabetizador. Esses elementos colocaram a prática pedagógica frente a novas abordagens de ensino, que vão além das metodologias tradicionais.

Emília Ferreiro trouxe à tona aspectos relevantes para o debate em torno do processo de aprendizagem da escrita e deslocou a exclusividade dada aos métodos de ensino. $\mathrm{O}$ resultado de suas investigações acerca da psicogênese da língua escrita (1985), em colaboração com Ana Teberosky, ressaltou a importância dos aspectos construtivos da aprendizagem e demonstrou que na busca para compreensão e apropriação do sistema alfabético, a criança formula importantes questionamentos a respeito da língua.

Mortatti (2000), os resultados provenientes dessas investigações possibilitaram uma revolução conceitual em relação às concepções tradicionais de ensino, instaurando "um novo paradigma para a interpretação do modo pelo qual a criança aprende a ler e a escrever" (AZENHA, 2006, p.42-43), permitindo questionar o que antes era considerado 
basilar para uma prática eficiente. Desse modo, ao buscar compreender a natureza do desenvolvimento da língua escrita, Ferreiro e Teberosky (1985) descobriram a existência de um percurso evolutivo realizado pelas crianças para apropriar-se do sistema de escrita. Verificou-se que o que antes a criança produzia em termos de erros na grafia são, do ponto de vista construtivo, tentativas de compreender o sistema alfabético, isto é, "a escrita produzida é fruto da aplicação de esquemas de assimilação ao objeto de aprendizagem (a escrita), formas utilizadas pelo sujeito para interpretar e compreender o objeto" (AZENHA, 2006, p.45).

Nesse percurso cognitivo, pode-se distinguir três períodos pelos quais é possível perceber o desenvolvimento infantil e as estratégias utilizadas por elas para a apropriação da escrita: "I. Distinção entre o modo de representação icônico e não-icônico; 2. A construção de formas de diferenciação (eixos qualitativo e quantitativo); 3. E a fonetização da escrita (que se inicia com um período silábico e culmina no período alfabético)” (FERREIRO, 1989, p.19).

No primeiro período, marcado pela diferença entre o modo de representação icônico e não icônico, estão presentes duas distinções básicas: desenho e escrita. Ao intercalar esses dois elementos, a criança demonstra certa incerteza quanto à definição da escrita, "registro do significado ou registro de palavras?” (AZENHA, 2006, p.75). Esse recurso está presente, também, como forma de atribuir significado e justificar a escrita produzida. Contudo, nesse momento, a criança já reconhece a diferença básica entre o desenho e a escrita.

A partir desse período, é possível perceber um esforço intelectual das crianças para criar distinções no interior das palavras, construindo, assim, bases importantes para a inserção no segundo estágio. Estas construções podem ser em nível intrafigurais e interfiguraisı, e correspondem às propriedades que uma produção escrita deve possuir para poder ser interpretável. Nessa fase, a preocupação da criança reside em estabelecer certa quantidade de caracteres e na importância de traçar diferenças internas nas palavras (FERREIRO, I989, p.20). Conforme seu repertório de letras, elas exploram variadas combinações para atribuir significado à escrita. Essas características sinalizam o nível présilábico e, nesse momento, ainda não há a compreensão da relação existente entre a fala e a escrita. 
O período de fonetização da escrita inicia-se quando as crianças percebem que a escrita pode representar à fala. Estabelece-se, assim, a entrada no período silábico. O elemento crucial nesse nível é a atribuição de um valor silábico a cada registro escrito, seja um número ou uma letra. Progressivamente, a criança vai compreendendo a relação entre as letras e os sons, e a partir daí introduz o período silábico-alfabético. "É um momento de transição, em que a criança, [...] ensaia em alguns seguimentos a análise da escrita como fonemas" (AZENHA, 2006, p.9I). Ao buscar aproximação com o princípio convencional, ingressa no nível alfabético. Nesse momento, a criança já compreende o modo de construção do sistema de escrita e é capaz de realizar uma análise de cada fonema das palavras produzidas. IRefere-se aos aspectos qualitativos e quantitativos da escrita. Intrafigurais: a criança preocupa-se com certa quantidade de letras; Interfigurais: a preocupação está na variação interna das letras para a escrita das palavras.

Essas contribuições permitiram o conhecimento de como as crianças desenvolvem seu aprendizado, evidenciando suas estratégias e demonstrando que esses processos compõem elementos maiores do que o proposto pelas teorias associacionista e empirista. Refletindo, desse modo, em outra forma de conceber as aprendizagens da leitura e escrita, em que a criança assume seu papel como sujeito ativo e construtor do seu conhecimento.

\section{${ }_{3}$ CONCLUSÃO}

O trabalho didático-pedagógico de alfabetização baseado na concepção empirista e a forma como sua prática didática se estabelece, está diretamente relacionado às concepções sobre o processo de alfabetização. Conseqüentemente, isso interfere na maneira como as crianças controlam a linguagem. As situações de aprendizagem em que os alunos se colocam fornecem conhecimentos básicos do sistema alfabético.

Assim, o trabalho de alfabetização pedagógica favorece a apropriação do sistema de escrita dos alunos. Por fim, o trabalho pedagógico voltado para a compreensão e reflexão sobre a linguagem escrita é importante para a introdução das crianças no universo literário, essencial para dar sentido ao uso da língua. 


\section{REFEÊNCIAS}

AZENHA, Maria da Graça. Construtivismo: de Piaget a Emília Ferreiro. Série Princípios. 8 ed. São Paulo: Ática, 2006.

BARBOSA, José. Juvêncio. Alfabetização e Leitura. 2aㅡ Ed. rev. São Paulo: Cortez, 1994.

CORREAA Vilma Reche. Método silábico: do passado à atualidade. In: Faria DS, organizador. Alfabetização: práticas e reflexões subsídios para o alfabetizador. Brasília: Universidade de Brasília; 2003.

FERREIRO, Emília. Com todas as letras. São Paulo: Cortez, 2oor. . Reflexões Sobre Alfabetização. São Paulo: Cortez, 1989. TEBEROSKY, Ana. Psicogênese da língua escrita. Porto Alegre: Artes Médicas, 1985.

FRADE, Izabel Cristina Alves da Silva. Métodos de alfabetização, métodos de ensino e conteúdos da alfabetização: perspectivas históricas e desafios atuais. Educação: revista do centro de educação - UFSM, 2007. Disponível em: http://cascavel.ufsm.br. Acesso em IO/II/ 202I.

LANKSHEAR, Colin; KNOBEL, Michele. Pesquisa Pedagógica: Do projeto à implementação. Porto Alegre: Artmed, 2008.

LIMA, Paulo Gomes; DOMINGUES, Jacqueline Lima. Família e aprendizagem dos filhos na escola: algumas pontuações a partir da percepção de professores. Acta Científica. Ciências Humanas, v. 2, 2007.

LÜDKE, Menga; ANDRÉ, Marli. Pesquisa em educação: abordagens qualitativas. São Paulo: EPU, 1986. MORAIS, Arthur. Gomes. Concepções e metodologias de 
Alfabetização: por que é preciso ir além da discussão sobre velhos "métodos"? In: Anais do XIII Encontro Nacional de Didática e Prática de Ensino. Recife: UFPE, 2006. Disponível: http://portal.mec.gov.br. Acesso em Io/II/202I.

SOARES, Magda. Alfabetização e letramento. 2. ed. São Paulo: Contexto, 2004. WEISZ, Telma. As contribuições da psicogênese da língua escrita e algumas reflexões sobre a prática educativa de alfabetização. In: Ciclo básico em jornada única: uma nova concepção de trabalho pedagógico. São Paulo: SE/CENP, 1999. V.i p.39-46. Disponível em: https://www.scribd.com. Acesso em Io/II/202I. 